\title{
Studi Perencanaan Instalasi Pengolahan Limbah Lindi Pada TPA Griyo Mulyo Kabupaten Sidoarjo
}

\author{
Feqinansyah Gerizepta Mahendra ${ }^{1}$, Erina Rahmadyanti ${ }^{2}$ \\ ${ }^{1}$ Program Studi Teknik Sipil, Fakultas Teknik, Universitas Negeri Surabaya

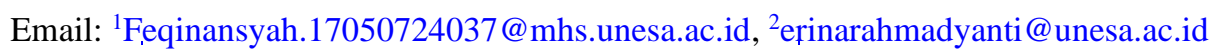

\begin{abstract}
The growth in the number of people from year to year always has an impact on increasing the amount of waste up to 19\%, including in Sidoarjo Regency where the processing is carried out at the Griyo Mulyo TPA. This TPA has a capacity of $8 \mathrm{Ha}$, with leachate processing facilities that refer to waste processing standards using standardized regulations, name-ly Government Regulation No. 27 of 2020 concerning Special Waste Management. Every TPA basically has to have a leachate processing installation, but in reality the Griyo Mulyo TPA has this installation but it is not yet operating. This study aims to plan a leachate treatment plant according to the standards of the Minister of Environment and Forestry Regulation No. P59 regarding Leachate Quality and for the $B O D$ s content is 150 milligrams/liter and the COD portion is 300 milligrams/liter. Meanwhile, the Griyo Mulyo TPA has a BODs level of $944.7 \mathrm{mg} / \mathrm{l}$ and a COD level of $3145.84 \mathrm{mg} / \mathrm{l}$. This shows a non-compliance with the Minister of Environment and Forestry Regulation Number P59. The method used is a re-planning and descriptive method using data that has been obtained from the Department of Environment and Hy-giene. The calculation results show that the leachate treatment plant design consists of a leachate treatment unit and the design and analysis of the leachate treatment unit with results that are not in accordance with the leachate quality stand-ards.
\end{abstract}

Keywords: Leachate, Research, Waste Management, Sidoarjo

\begin{abstract}
Abstrak
Pertumbuhan jumlah masyarakat dari tahun ketahun senantiasa berdampak pada pertambahan jumlah sampah hinga $19 \%$ termasuk di Kabupaten Sidoarjo yang pengolahannya dilakukan di TPA Griyo Mulyo. TPA ini memiliki kapasitas $8 \mathrm{Ha}$, dengan fasilitas pengolahan limbah lindi yang mengacu pada standar pengolahan sampah yang menggunakan pera-turan yang dibakukan yaitu Peraturan Pemerintah No 27 Tahun 2020 mengenai Pengolahan sampah khusus. Setiap TPA pada dasarnya harus memiliki instalasi pengolahan lindi, namun pada kenyataannya TPA Griyo Mulyo mempunyai in-stalasi tersebut tetapi belum beroperasi. Penelitian ini bertujuan untuk merencanakan instalasi pengolahan lindi sesuai standard dari Peraturan Menteri LHK No P59 tentang Mutu Lindi dan untuk kadar BODs ialah 150 miligram/liter dan bagian COD ialah 300 miligram/liter. Sedangkan pada TPA Griyo Mulyo ini mempunyai kadar BODs adalah $944,7 \mathrm{mg} / \mathrm{l}$ dan untuk COD adalah 3145,84 mg/l. Hal ini menunjukkan ketidaksesuaian terhadap Peraturan Menteri LHK Nomor P59. Metode yang digunakan adalah metode perencanaan ulang dan deskriptif menggunakan data yang telah diperoleh dari Dinas Lingkungan Hidup dan Kebersihan. Hasil perhitungan menunjukkan bahwa rancangan instalasi pengolahan lindi terdiri dari unit pengolahan air lindi dan desain serta menganalisis unit pengolahan lindi dengan hasil yang tidak sesuai dengan standard baku mutu lindi.
\end{abstract}

Kata Kunci: Lindi, Penelitian, pengolahan Sampah, Sidoarjo

\section{Pendahuluan}

Seiring bertambahnya jumlah penduduk di Indonesia akan berdampak pada peningkatan jumlah sampah. Kondisi ini juga dialami oleh Kabupaten Sidoarjo. Lindi adalah cairan yang merembes melalui tumpukan sampah dengan membawa materi terlarut atau tersuspensi terutama hasil proses dekomposisi materi sampah [1]. Berdasarkan data BPS sebagaimana pada Tabel 1. Total penduduk di Kabupaten Sidoarjo ini pada tahun 2016 hingga 2019 cenderung mengalami peningkatan sebanyak 5\% dimana pertahunnya meningkat sekitar $1 \%$ hingga $2 \%$. 


\begin{tabular}{|c|c|c|c|c|}
\hline Nama Daerah & Jumlah 2016 & Jumlah 2017 & Jumlah 2018 & Jumlah 2019 \\
\hline Waru & 238,210 & 240,142 & 252,573 & 262,463 \\
\hline Taman & 231,251 & 236,452 & 239,251 & 243,458 \\
\hline Sidoarjo & 224,253 & 224,862 & 225,012 & 225,646 \\
\hline
\end{tabular}

Data pada Tabel 1 dan Tabel 2 memperlihatkan jika pad pertumbuhan penduduk dari tahun ketahun semakin meningkat dan menimbulkan terjadinya pertumbuhan pada sampah di Kabupaten Sidoarjo. Data di lapangan terhadap peningkatan jumlah sampah dibuktikan dengan data sebagaimana terdapat pada tabel 2 .

Tabel 2. Pertumbuhan sampah per tahun di Kabupaten Sidoarjo

\begin{tabular}{cll} 
Tahun & & Jumlah \\
\hline 2016 & & 200 ton \\
2017 & & 250 ton \\
2018 & & 390 ton \\
2019 & 450 ton \\
\hline
\end{tabular}

Sumber: Dinas Lingkungan Hidup dan Kebersihan Kabupaten Sidoarjo

Data Empiris adalah suatu metode penelitian hukum yang menggunakan data asli atau hasil dari terjun langsung kelapangan, empiris juga diambil dari perilaku manusia, baik perilaku verbal yang didapat dari wawancara maupun perilaku nyata yang dilakukan melalui pengamatan langsung[2]

Pertumbuhan limbah sampah ini hal dimana harus ditangani dengan baik, berdasarkan UndangUndang tentang pengolahan limbah samptah Nomor 18 Tahun 2008, mendefinisikan limbah sampah yaitu barang tidak layak pakai. Pengelolahan sampah yaitu kegiatan yang dilakukan untuk mengurangi jumlah sampah yang dapat dimanfaatkan, baik dengan peranan yang sama atau dengan peranan yang berbeda. Tujuan pengolahan sampah adalah untuk mengurangi dampak yang negatif terhadap lingkungan, agar limbah sampah akan ditaruh ke TPA Griyo Mulyo dan akan lebih kecil jumlahnya. Pengelolaan sampah di Kabupaten Sidoarjo dilakukan di TPA Griyo Mulyo. TPA tersebut berlokasi di Desa Kupang JL. Raya Kallisogo, Kecamatan Jabon, Sidoarjo serta memiliki luas sekitar 8 Ha. Proses pada gambar 1, dapat dilihat bahwa model pengolahan sampah di TPA Griyo Mulyo.

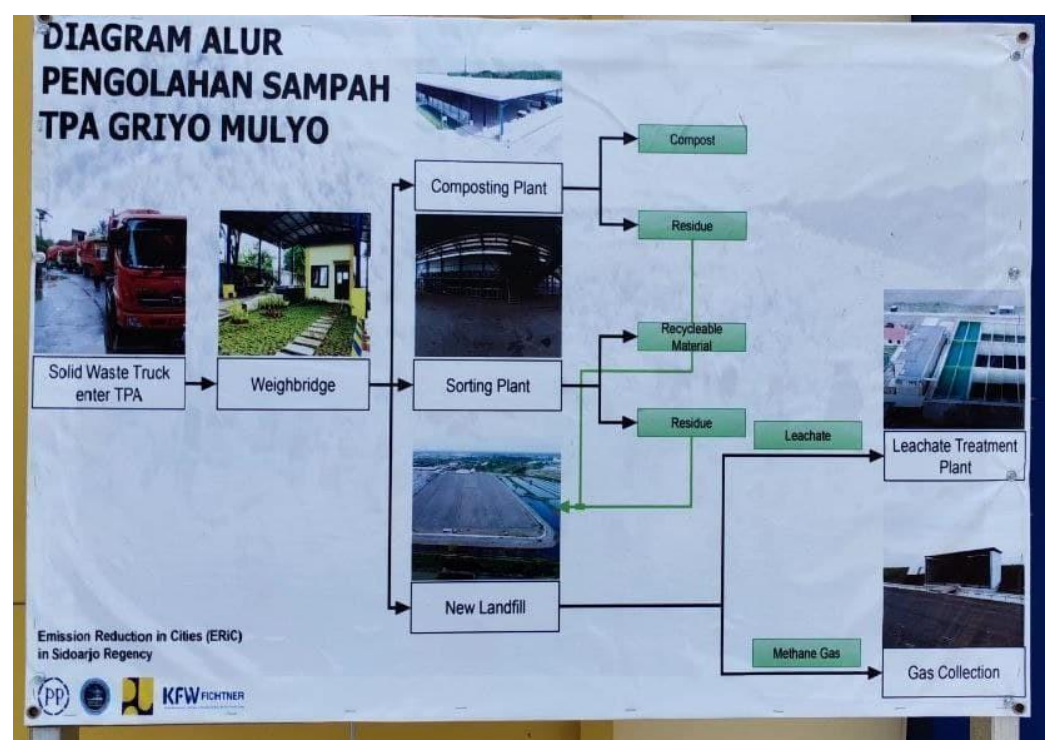

Gambar 1. Model Pengolahan Sampah 
Pengolahan sampah di TPA Griyo Mulyo mempunyai beberapa unit pengolahan seperti composting plant yang berfungsi untuk memilah sampah tanaman dan dijadikan sebagai pupuk kompos, sedangkan sorting plant berfungsi untuk mengolah sampah tanaman agar bisa dijadikan sebagai bahan baku kembali, dan terakhir yaitu new landfill yang berfungsi sebagai pengolahan lindi dimana lindi dihasilkan pada proses penumpukan sampah yang akan ditandai dengan adanya perubahan fisik pada sampah tersebut. Pada saat ini TPA Griyo Mulyo sudah memiliki unit pengolahan lindi namun masih belum beroperasi dikarenakan pengolahan lindi tersebut sedang dilakukan perluasan lahan agar dapat menampung banyak sampah termasuk limbah lindi.

Lindi yaitu cairan yang meresap ke luar melalui tempat pembuangan sampah, membawa zat yang tela larut atau tersuspensi, terpenting sebagai hasil dari olahan penguraian sampah[3]. Lindi juga memiliki karakteristik benar-benar mempunyai variasi menurut proses dimana itu akan terjadi selanjutnya didalam lindi, dimana akan memasuki proses nyata, biologis serta kimia. Aspek yang mempengaruhi proses lindi antara lain: jenis limbah, tempat lindi, hidrogeologi dan yang terpenting yaitu sistem operasi [4]. Pengolahan lindi yang tidak tepat akan mencemari lingkungan. Beberapa penelitian menyebutkan pencemaran lindi berdampak pada lingkungan dan menyebabkan pencemaran terhadap lahan kerja masyarakat yaitu sawah dan kolam [5].

Proses pengolahan lindi pada penelitian-penelitian sebelumnya menggunakan koagulasi flokulasi, yang merupakan teknologi pengolahan yang relatif sederhana untuk pengolahan lindi. Menggunakan metode ini dapat menyingkirkan bahan organik serta polutan yang lain dari lindi TPA dengan memanfaatkan koagulan. Koagulan yang umum digunakan merupakan koagulan anorganik semacam PAC, besi sulfat serta aluminium sulfat. Akan tetapi, bahan ini mempunyai tingkat tidak stabil yang dimana akan mengelurkan tanah basah dimana itu akan beresiko untuk area sekitar [6]. Mengutip dari jurnal [7] menyatakan bahwa mempunyai cara alternatif untuk mengatasi permasalahan lindi yaitu dengan cara meningkatkan sistem perencanaan pengolah air lindi memanfaatkan cara mengalirkan air lindi ke dalam suatu reaktor yang disebut dengan biofilter anaerob-aerob. Adanya sistem tersebut bisa menyanggupi untuk mempercepat waktu, agar area yang dibutuhkan agar pengolahan air lindi tersebut tidak terlalu besar. Pengeluaran dari air lindi yang diinginkan agar bisa memenuhi standar yang diperbolehkan agar bisa dibuang ke sungai dan tidak mencemari lingkungan. Proses pengolahan lindi juga bisa menggunakan proyeksi jumlah penduduk yang banyak dengan menggunakan metode estimasi [8].

Berpijak pada beberapa kajian tersebut maka penelitian ini direncanakan menggunakan proyeksi jumlah penduduk dengan cara estimasi dan mencari prediksi jumlah air untuk pengolahan lindi di TPA Griyo Mulyo. Hasil riset ini diharapkan bisa jadi pertimbangan bagi stakeholder terkait di dalam pengembangan pengolahan lindi di TPA Griyo Mulyo.

\section{Metode}

Tahapan metode penelitian ini menggunakan metode kuantitatif dimana dapat digunakan sebagai proses menemukan pengetahuan dimana menggunakan data berupa angka sebagai alat menganalisis tentang apa yang ingin diketahui [9]

Tahapan sistem yang digunakan supaya bisa memperkirakan jumlah penduduk yang terus miningkat banyak. Sistem perkiraan populasi dihitung menggunakan 3 sistem perbandingan. Ketiga sistem tersebut adalah: (1) Sistem Geometri merupkan asumsi bahwa laju perubahan penduduk selama bertahun tahun bervariasi. (2) Sistem Aritmetika merupakan pertumbuhan penduduk menggunakan basis suku bunga. dan (3) Sistem Least Square dan Grafik merupakan tata cara agar memperoleh setiap korelasi antara sumbu Y serta sumbu X, dimana Y merupakan populasi serta X merupakan tahun. [10]

\section{Hasil dan Pembahasan}

Dalam proyeksi jumlah penduduk dimana sistem yang digunakan supaya bisa memperkirakan jumlah penduduk yang terus miningkat banyak. Sistem perkiraan populasi dihitung menggunakan 3 sistem perbandingan. 
1) Metode Aritmatika

Metode aritmetika didasarkan pada asumsi bahwa laju perubahan selama bertahuntahun bervariasi, dan bahwa populasi tumbuh pada laju yang berbeda setiap tahun [11]. Bentuk matematis dari model aritmetika adalah sebagai berikut:

Rumus yang digunakan:

$\mathrm{Pt} \quad=\mathrm{P} 0(1+\mathrm{rt})$

Dengan:

$\mathrm{Pt} \quad=$ total populasi penduduk pada $\mathrm{t}$ tahun

$\mathrm{P} 0 \quad=$ awal tahun populasi $=238,210$

$\mathrm{r} \quad \quad=$ laju peningkatan penduduk $=2,21 \%$

$\mathrm{t} \quad=$ Waktu $=2019-2016=3$

$\mathrm{Pt} \quad=238,210(1+0,0221 \times 3)$

$=254,003$ jiwa

$=(254,003 / 12) \times 100 \%=0.21 \%$

Berdasarkan penghitungan, perkiraan jumlah penduduk Kabupaten Sidoarjo Kecamatan Waru pada tahun 2019 adalah 254,003 jiwa.

2) Metode Gemetri

Metode ini mengasumsikan pertumbuhan penduduk menggunakan basis suku bunga [10]. Dengan asumsi tingkat pertumbuhan penduduk tahunan yang sama, bentuk matematis dari tata cara geometris ialah seperti dibawah ini:

Rumus yang digunakan:

$\mathrm{Yn}=\mathrm{Pt}(1+\mathrm{r})^{\mathrm{n}}$

$r=($. Pt

)$^{(1 / t)}$

$-1$

Po

Dengan:

Yn $=$ Total penduduk pada tahun ke-n Po

$=$ Total penduduk pada tahun awal $\mathrm{Pt}=$

Total penduduk data akhir tahun $\mathrm{N}=$ Masa

perbedaan waktu

$\mathrm{R} \quad=$ laju peningkatan penduduk (\%)

$\mathrm{t} \quad=$ Masa perbedaan waktu tahun data $(\mathrm{n}-1)$

$\mathrm{r} \quad=\left(\frac{254,003}{238,210}\right)(1 / 3)-1$

$=0,0216 \%$

Sehingga laju pertumbuhan penduduk pada Kabupaten Sidoarjo per tahunnya adalah 0,0216 atau 2,16 persen.

3) Metode Least Square dan Grafik

Sistem Grafik merupakan tata cara agar memperoleh setiap korelasi antara sumbu Y serta sumbu $\mathrm{X}$, dimana $\mathrm{Y}$ merupakan populasi serta $\mathrm{X}$ merupakan tahun, dengan cara menggambar garis antara perhitungan ini serta jumlah kuadrat dari jarak deviasi antara perhitungan serta garis yang ditarik minimum[12]. Wujud matematis model kuadrat terkecil ialah seperti dibawah ini: 
Rumus yang digunakan:

$$
\begin{aligned}
& \text { Yn } \quad=a+b \\
& \text { a } \left.\quad=\sum y \cdot \sum_{n} X^{2} X^{2}-\sum X X \sum^{2} X Y\right)^{2} \\
& \text { b } \quad=\sum_{n \sum X Y-\sum X X \sum X Y} X X^{2}-\left(\sum X\right)^{2}
\end{aligned}
$$

$$
\begin{aligned}
& \text { Dengan } \\
& \text { Yn } \quad=\text { Total populasi penduduk dalam tahun } n \\
& \text { a } \quad=\text { Tetapan } / \text { Konstanta } \\
& \mathrm{b}=\text { Koefisien pertumbuhan populasi } \\
& \mathrm{X}=\text { Pertumbuhan tahunan } \\
& \mathrm{n} \quad=\text { total data } \\
& a=254,003323 \times 2019^{2}-254,003323 \times 512832,7091 \\
& 4 \times 254,003323^{2}-(254,003323)^{2} \\
& =4676,484 \\
& \text { b } \quad=51 \cdot 2832 \times 7091-254,003323 \times 512832,7091 \\
& 4 \times 254,003323^{2}-(254,003323)^{2} \\
& =-670,350 \\
& \text { Yn } \quad=a+b=4676,484+(-670,350)=4006,134 \\
& =(4006,134 / 12) \times 100 \%=3,33 \%
\end{aligned}
$$

Ketiga perhitungan diatas didapatkan bahwa tata cara Least Square mempunyai nilai koefisien yang paling mendekati lima dikarenakan nilai 5\% diperoleh dari selisih data dari tahun 2016 hingga 2019. Jadi, dapat menggunakan tata cara ini untuk memprediksi populasi berdasarkan jumlah hasil proyeksi masyarakat Kabupaten Sidoarjo. Pada gambar 2 ditunjukkan proses grafik prediksi populasi.

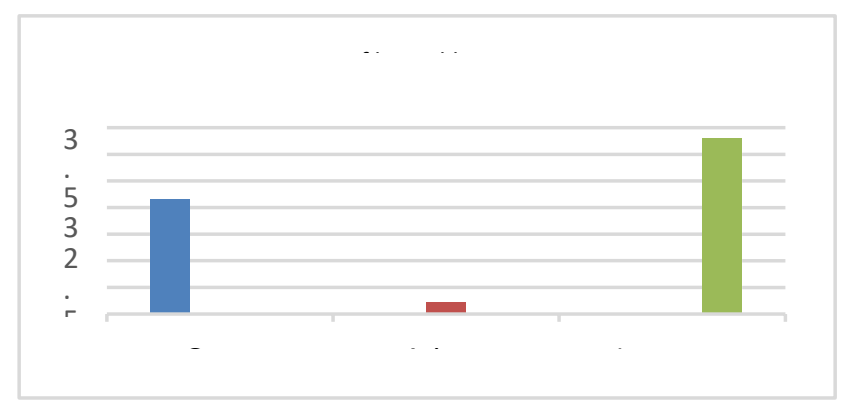

Gambar 2. Grafik Prediksi Populasi

Keperluan air pada suatu wilayah tertentu digunakan persamaan yaitu produk penduduk dan standar kebutuhan air [13]. Berikut merupakan rumus umum yang dipakai dalam penghitungan adalah:

Qy $\quad=$ dy $\quad$ py

Diketahui:

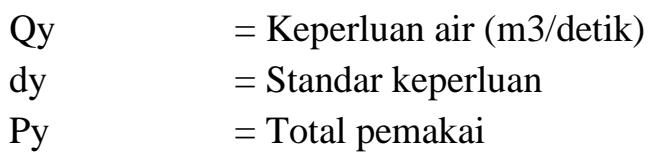


Kabupaten Sidoarjo terdapat dua kelompok penduduk pedesaan dan perkotaan dengan keperluan air yang berbeda, tenang hal keperluan penduduk perkotaan terhadap air sejumlah 120 liter/hari/orang yang dimana kurang lebih sekitar 43,8 m3/orang/tahunnya, dan keperluan penduduk desa terhadap air sejumlah 60 liter/hari/orang yang dimana kurang lebih sekitar 21,9 m3/orang/tahunnya [14]. Pada produksi limbah lindi pada TPA Griyo Mulyo Sidoarjo adalah 0,7 $\mathrm{m} 3$ per hari [15]

\section{4) Timbunan Lindi}

Timbunan lindi diproyeksikan akan memakai hasil perhitungan dari curah hujan sehingga dapat melihat di perhitungan curah hujan yang kurang lebih 10 tahun, dan didapat asumsi volume atau total dari air lindi yang keluar. Ditaksir volume air lindi yang terdapat pada area wilayah timbunan limbah tersebut dikalikan curah hujan dan di kalikan lagi dengan pengaliran lalu dikalikan dengan ketetapan 0,278 kemudian di kalikan kembali dengan adanya nilai perkiraan [16] Berikut pada tabel 3 adalah data curah hujan yang ada di Kabupaten Sidoarjo.

Tabel 3. Data perhitungan curah hujan di Kabupaten Sidoarjo 2018

\begin{tabular}{|c|c|c|c|c|}
\hline Bulan & Tahun 2017 & Tahun 2018 & Tahun 2019 & Tahun 2020 \\
\hline Januari & - & 346 & 487 & 173 \\
\hline Februari & 490 & 336 & 451 & 377 \\
\hline Maret & 247 & 457 & 332 & 325 \\
\hline April & 235 & 257 & 54 & 175 \\
\hline Mei & - & - & - & - \\
\hline Juni & 36 & 49 & 0.8 & 20 \\
\hline Juli & - & - & - & - \\
\hline Agustus & - & - & - & - \\
\hline September & - & - & - & - \\
\hline November & 119 & 76 & 26 & 216 \\
\hline Desember & 209 & 207 & 117 & 198 \\
\hline
\end{tabular}

Sumber: Dinas Pekerjaan Umum dan Penataan Ruang Kabupaten Sidoarjo

Q

Diketahui:

Q

$\mathrm{K}$

$\mathrm{C}$

I

A

Q

$$
=\mathrm{K} \times(0,278 \times \mathrm{C} \times \mathrm{I} \times \mathrm{A})
$$

= rencana pembuangan air lindi $\mathrm{m} 3 /$ hari

$=$ koefisien pendekatan $(0,60-0,70)$

$=$ Koefisien aliran $(0,3-0,4)$

$=$ intensitas curah hujan $(\mathrm{mm} / \mathrm{hari})=17,5 \mathrm{~mm} /$ hari

$=$ area luas galian TPA

$=0,70 \times(0,278 \times 0,4 \times 17,5 \times 8)$

$=10,90 \mathrm{~m} 3$ per hari.

Data debit air lindi ini hingga diketahui debit air hujan pada TPA Griyo Mulyo Sidoarjo ialah $34,87 \mathrm{~m} 3$ per hari.

\section{5) Instalasi Pengolahan lindi}

TPA Kabupaten Sidoarjo yang dimana instalasi pengolahan limbah pertama yang disarankan yaitu kolam stabilisasi secara alamiah, diteruskan melalui aliran yang dialirkan kepada tanaman dan ke lahan sanitasi berupa kolam anaerob [17]. Pengolahan limmbah kedua Pengelolaandairdlindiddapat dilakukan dengandcaradmencegahdair permukaan masuk kedalam lahan dandtimbunan sampah yaitu dengan mengendalian air permukaan, pengisolasian timbunan sampah dengan lapisan tanah penutup, mengolah air lindi menurut kadar kandungan yang ada didalamnya sehingga air lindi dapat di salurkan ke pembuangan badan air terdekat [18]. 
Metode ini juga berupa aliran pipa yang mengumpulkan lindi dan bermaksud agar dapat menjadi pengumpul aliran air pada saat hujan dan ketika area sedang tidak berjalan (belum tersedia) agar kedepannya bisa mengalir pergi ke arah sungai [19]. Pada saat yang sama, setelah operasi lahan selesai, pipa drainase yang menuju kepada sungai yang telah ditutup dan air lindi mengalir kepada proses pengolahan lindi tersebut. Pada gambar 3 ditunjukkan alur pengolahan air limbah lindi.

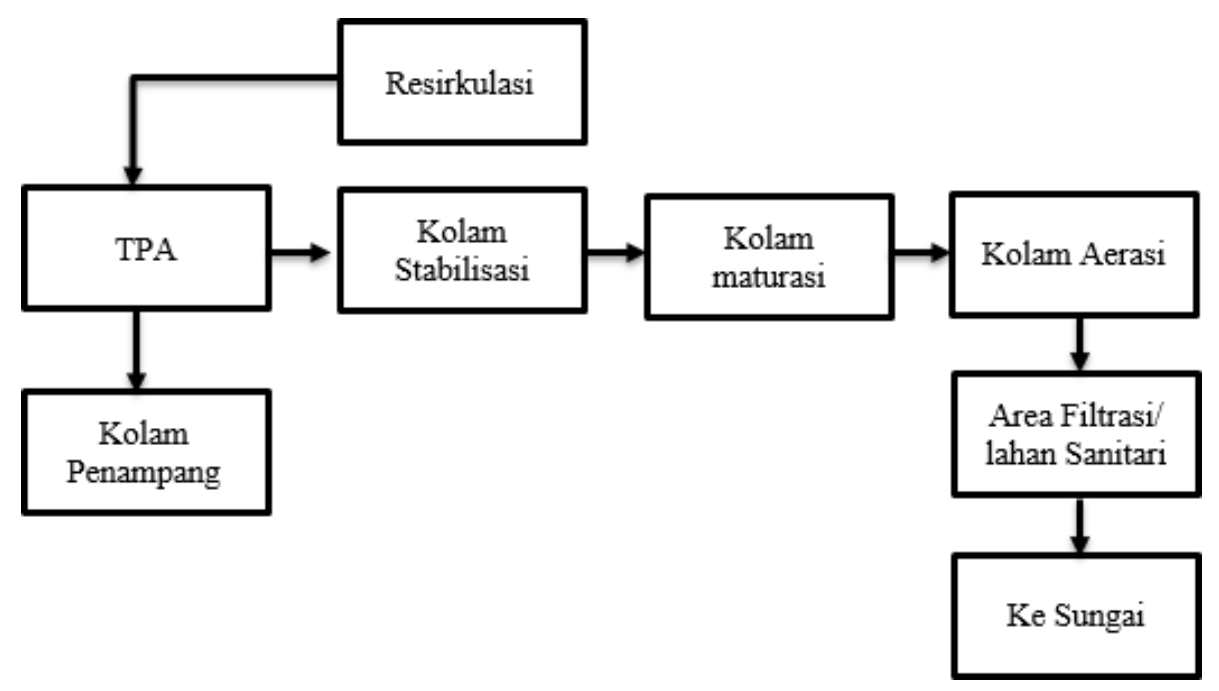

Gambar 3. Diagram pengolahan lindi

Peraturan yang berlaku di Indonesia untuk kualitas produk olahan dimana Kolam stabilisasi mempunyai hasil pengolahan yaitu seperti berikut:

- Kemampuan pengolahan $(60-85 \%)$

- Hasil pepercobaan dikandungan BOD5 yang terdapat pada TPA Griyo Mulyo = 944,7 mg/l

- Hasil pepercobaan dikandungan COD pada TPA Griyo Mulyo = 3145,84 mg/l [20]

Tabel 7. Beberapa standar yang ada dan diberlakukan pada negara Indonesia

\begin{tabular}{|c|c|c|c|c|c|}
\hline klasifikasi & $\begin{array}{c}\text { BOD5 } \\
\mathrm{mg} / \mathrm{L}\end{array}$ & $\begin{array}{c}\mathrm{COD} \\
\mathrm{mg} / \mathrm{L}\end{array}$ & $\mathrm{pH}$ & $\begin{array}{c}\sum \mathrm{N} \\
\text { Anorganik }\end{array}$ & $\begin{array}{c}\mathrm{Ss} \\
\mathrm{Mg} / \mathrm{L}\end{array}$ \\
\hline Gol I & 10 & 20 & 8 & 10,44 & 50 \\
\hline Gol II & 40 & 80 & 8 & 20 & 100 \\
\hline Gol III & 100 & 200 & 8 & 32 & 200 \\
\hline Gol IV & 200 & 400 & 8 & 70 & 400 \\
\hline
\end{tabular}

Sumber: Peraturan Menteri Lingkungan Hidup 03/91

6. Pengolahan Tanah

Metode pengolahan tanah adalah metode pengolahan limbah air lindi yang menggunakan cara merembeskan cairan air lindi kepada suatu area lahan yang disana telah ditanamkan tumbuhan yang terpilih[21]. Tumbuhan yang dimana itu adalah terpilih yaitu tumbuhan yang memiliki sifat atau karakteristik sebagaimana berikut ini:

- Tanaman berbulu, tanaman yang bisa menyerap air lebih praktis kemudian lebih banyak menguap.

- Mempunyai nilai yang ekonomis atau bisa dibeli dengan harga murah untuk dibeli karena tanaman tersebut akan terjadi perantara

pada gambar 4 ditunjukkan alur dari Leachate Treatment Plant. 


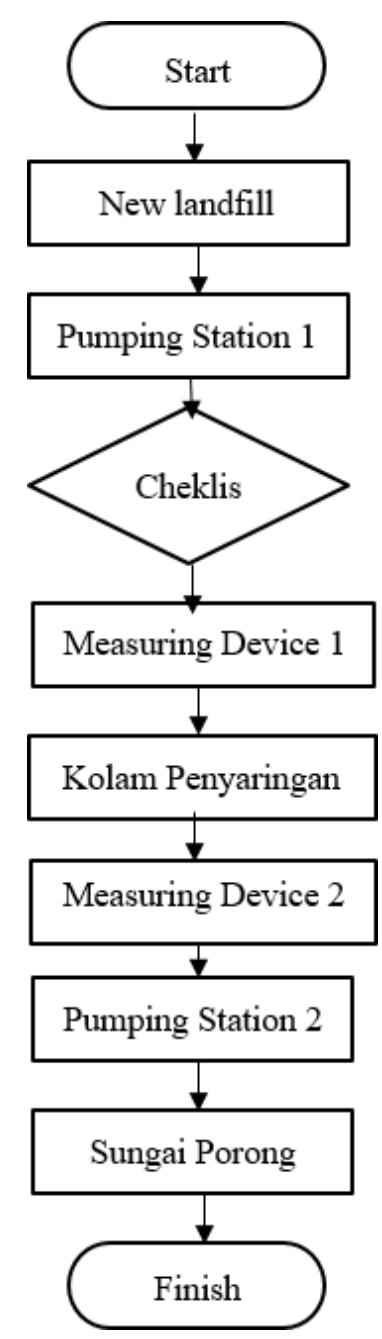

Gambar 4. flowchart pengolahan lindi

\section{Kesimpulan}

Dari apa yang telah dijelaskan dimana ini bisa ditarik kesimpulan yang diperoleh yaitu kebutuhan lahan TPA perlu ditambah agar dapat menampung sampah lebih banyak lagi pada TPA sebelumnya.

Debit lindi di tangki penyimpanan yang direncanakan $\mathrm{Q}=10,90 \mathrm{~m} 3$ per hari. Pengolahan limbah juga mempunyai kadar COD $=3145,84$ miligram/liter dan BOD5 $=944,7$ miligram/liter sesudah melewati proses pengolahan lindi ini yang dimana COD menjadi $=263,2$ miligram $/ 1$ sedangkan BOD5 $=78,7$ miligram/liter. Proses hasil pengolahan ketiga, pengolahan ketiga tersebut sudah mencapai standard dari Peraturan Menteri LHK Nomor P59.

Metode rapid infiltration plant memudahkan agar lebih efektif dan ekonomis karena tumbuhan tersebut akan menjadi medianya.

\section{Referensi}

[1] R. N. Sari and A. Afdal, "Karakteristik Air Lindi (Leachate) di Tempat Pembuangan Akhir Sampah Air Dingin Kota Padang," J. Fis. Unand, vol. 6, no. 1, pp. 93-99, 2017, doi: 10.25077/jfu.6.1.93-99.2017.

[2] K. Benuf and M. Azhar, "Metodologi Penelitian Hukum sebagai Instrumen Mengurai Permasalahan Hukum Kontemporer," Metodol. Penelit. Huk. sebagai Instrumen Mengurai Permasalahan Huk. Kontemporer, vol. 3, no. 2, pp. 145-160, 2019. 
[3] T. Istirokhatun, M. F. Z, and H. Susanto, "Pengolahan Leachate Tempat Pembuangan Akhir Sampah Menggunakan Kombinasi Teknologi Membran Mikrofiltrasi dan Nanofiltrasi," J. Tek., vol. 72, no. 1, pp. 1-8, 2012.

[4] M. Ali, Rembesan Air Lindi (Leachate) Dampak Pada Tanaman Pangan dan Kesehatan. 2011.

[5] E. Hartini and Y. Yulianto, "Kajian Dampak Pencemaran Lindi Tempat Pemrosesan Akhir (TPA) Ciangir terhadap Kualitas Air dan Udara," J. Sains dan Teknol., vol. 4, no. 1, pp. 27-32, 2018.

[6] O. Violet, I. Ufomba, and M. Chys, "A comparative study on the efficiency of ozonation and coagulation-flocculation as pretreatment to activated carbon adsorption of biologically stabilized landfill leachate," vol. 43, pp. 335-342, 2015.

[7] N. I. Said and D. R. K. Hartaja, "Pengolahan Air Lindi Dengan Proses Biofilter Anaerob-Aerob Dan Denitrifikasi,” J. Air Indones., vol. 8, no. 1, 2018, doi: 10.29122/jai.v8i1.2380.

[8] C. Saleh and H. Purnomo, "Analisis efektifitas instalasi pengolahan limbah lindi Di TPA Supit Urang Kota Malang,” J. Tek. Pengair., vol. 5, no. 1, pp. 103-109, 2014, [Online]. Available: https://jurnalpengairan.ub.ac.id/index.php/jtp/article/view/209/203.

[9] Sugiyono, "Metode Penelitian Kuantitatif Kualitatif" dan R\&D.," 2007.

[10] A. Suheri, C. Kusmana, M. Y. J. Purwanto, and Y. Setiawan, "Model Prediksi Kebutuhan Air Bersih Berdasarkan Jumlah Penduduk di Kawasan Perkotaan Sentul City," J. Tek. Sipil dan Lingkung., vol. 4, no. 3, pp. 207-218, 2019, doi: 10.29244/jsil.4.3.207-218.

[11] J. Tipka, "PROYEKSI PENDUDUK BERLIPAT GANDA DI KABUPATEN MALUKU TENGAH (Population Projection Than Doubled in Central Maluku Regency)," J. barekeng, vol. 5, pp. 31-34, 2011.

[12] D. Sulistyono, "Analisis Sistem Pengelolaan Sampah Di Kecamatan Karangploso Kabupaten Malang," EXTRAPOLASI J. Tek. Sipil, vol. 6, no. 02, pp. 112-125, 2013, [Online]. Available: http://jurnal.untag-sby.ac.id/index.php/EXTRAPOLASI/article/view/842.

[13] A. Fauzi, Pemanfaatan Sistem Informasi Geografis (sig) untuk Analisis Kelayakan Perluasan Tempat Pembuangan Akhir (TPA) Sampah Cipeucang Kota Tangerang Selatan. 2016.

[14] Badan Standar Nasional. 2012.

[15] DLHK, "Dinas Lingkungan Hidup dan Kebersihan Sidoarjo," 2020.

[16] M. Rijalurrahman, "PERENCANAAN TEMPAT PEMROSESAN AKHIR SAMPAH DENGAN MENGGUNAKAN METODE SANITARY LANDFILL ( Studi kasus: TPA Randuagung Kabupaten Malang ) DESIGN OF WASTE LANDFILL USING SANITARY LANDFILL ( Case study : Randuagung Landfill of Malang Regency ) dan Peraturan ," pp. 118125, 2017.

[17] M. Hadiwidodo, W. Oktiawan, A. R. Primadani, N. Parasmita, and I. Gunawan, "Pengolahan Air Lindi Dengan Proses Kombinasi Biofilter Anaerob-Aerob Dan Wetland," J. Presipitasi, vol. 9, no. 2, pp. 84-95-95, 2012, doi: 10.14710/presipitasi.v9i2.84-95.

[18] A. Nur, F. Busanto, and E. Rahmadyanti, "Analisa Dampak Saluran Lindi Terhadap Lingkungan Dilihat Dari Aspek Pengelolaan TPA,” J. Tek. Sipil, vol. 2, pp. 1-10, 2021.

[19] C. Saleh, "Lindi Sebagai Kontrol Pemenuhan Baku Mutu Sesuai Kepmen 03 / 91 ( Studi Kasus Pada Tpa Supit Urang Malang )," Media Tek. Sipil, vol. 10, no. 2, pp. 87-94, 2012.

[20] Menteri Lingkungan Hidup dan Kehutanan Republik Indonesia, "Peraturan Menteri Lingkungan Hidup dan Kehutanan Republik Indoneisa Nomor P.59/Menlhk/Setjen/Kum.1/7.2016 Tentang Baku Mutu Lindi Bagi Usaha dan/atau Kegiatan Tempat Pemrosesan Akhir Sampah,” Ber. Negara Republik Indones. Tahun 2016 Nomor 1050, pp. 1-12, 2016.

[21] N. Apriyani and R. Y. Lesmana, "PENGARUH AIR LINDI PADA TERHADAP pH DAN ZAT ORGANIK PADA AIR TANAH DI TEMPAT PENAMPUNGAN SEMENTARA KELURAHAN PAHANDUT KOTA PALANGKARAYA (Effect of Leachate to $\mathrm{pH}$ and Organic Substances of Ground Water in The Waste Transfer Station in Kelurahan Pahandut Ko," J. Mns. dan Lingkung., vol. 25, no. 2, p. 60, 2020, doi: 10.22146/jml.39489. 